\title{
PENGARUH STRATEGI PEMASARAN TERHADAP KEPUTUSAN PEMBELIAN ULANG PADA PRODUK SHARE TEA DI MANADO TOWN SQUARE 3 KOTA MANADO
}

\author{
Dhea Octaviani Sumaila \\ Joachim N. K. Dumais \\ Ellen G. Tangkere
}

\begin{abstract}
This study aims to determine the effect of marketing strategy on purchasing decisions on Share Tea products in Mantos 3 City Manado. This research is carried out for 3 months from February 2018 until April 2018. Data is done by using primary data and secondary data. Primary data was obtained by interview based on list of questionneire. Sampling method is Accidental Sampling. The total number of samples taken in this research is 60 people. The sampling process is conducted for 3 days conducted on Tuesdays, Wednesdays and Saturday by taking 20 sample per day. The results showed that product measured by number of varieties, quality and brand influence the buying decision. Place measured based on the location of the strategic place and the arrangement of interior decoration also affect the purchasy decision. The promotion measured based on the promotion given to the consumer influences the buying decision. While, the variable price measured by price, price of purchasing power, and price of quality product do not influence the repurchase decision.*Ir*.
\end{abstract}

Keywords: marketing strategy, buying decision, Share Tea, Town Square 3, Manado City.

ABSTRAK

Penelitian ini bertujuan untuk mengetahui pengaruh strategi pemasaran terhadap keputusan pembelian pada produk Share Tea di Manada Town Square 3 Kota Manado. Penelitian ini dilakukan selama 3 bulan dari Februari 2018 hingga April 2018. Data dilakukan dengan menggunakan data primer dan data sekunder. Data primer diperoleh dengan wawancara berdasarkan daftar kuesioner. Metode pengambilan sampel adalah Accidental Sampling. Jumlah sampel yang diambil dalam penelitian ini adalah 60 orang. Proses pengambilan sampel dilakukan selama 3 hari yang dilakukan pada hari Selasa, Rabu dan Sabtu dengan mengambil 20 sampel per hari. Hasil penelitian menunjukkan bahwa produk yang diukur dengan jumlah varian, kualitas dan merek mempengaruhi keputusan pembelian. Tempat diukur berdasarkan lokasi tempat yang strategis dan penataan dekorasi interior juga mempengaruhi keputusan pembelian. Promosi yang diukur berdasarkan promosi yang diberikan kepada konsumen memengaruhi keputusan pembelian. Sedangkan, harga variabel yang diukur berdasarkan harga, harga daya beli, dan harga kualitas produk tidak mempengaruhi keputusan pembelian kembali. *lrr*

Kata kunci: strategi pemasaran, keputusan pembelian, Share Tea, Town Square 3, Kota Manado.

\section{PENDAHULUAN}

\section{Latar Belakang}

Industri minuman berbahan dasar produk pertanian di Indonesia mengalami perkembangan, salah satunya di Kota Manado. Munculnya berbagai jenis minuman dengan tampilan dan rasa yang unik menarik para konsumen dari berbagai usia. Salah satu perusahaan industri minuman yang memiliki potensi pasar yaitu Share Tea. Share Tea merupakan salah satu perusahaan sekaligus merek produk minuman bubble tea yang mendunia. Bubble tea itu sendiri adalah minuman yang berbahan dasar teh dengan dikombinasikan berbagai varian rasa serta diberikan isian (topping) berupa jelly atau sejenisnya (Manasaputri, 2015).

Share Tea juga menyediakan tempat bagi konsumen untuk duduk bersantai sambil menikmati segarnya Share Tea. Hal tersebut mendorong anak muda untuk mengunjungi outlet Share Tea. Share Tea pertama kali membuka 
cabang outletnya di Kota Manado pada tahun 2013 di Manado Town Square 1 dan sampai saat ini Share Tea telah memiliki 4 Outlet di daerah Manado. Dalam perkembangannya, tingkat penjualan Share Tea mengalami pasang surut. Meraih kembali pasar yang telah menurun, dan untuk mempertahankan pasar yang telah diperolehnya adalah tantangan yang harus dihadapi.

Melihat kecenderungan konsumen di Kota Manado yang suka berpindah dari produk yang satu ke produk yang lain, dan keinginannya untuk mencoba berbelanja ditempat yang baru. Share Tea harus menerapkan strategi pemasaran yang baik dan tepat, agar ia dapat memberikan kepuasan yang lebih pada konsumen, di bandingkan dengan kepuasan yang diberikan oleh pesaingnya. Hal ini akan mempengaruhi konsumen untuk melakukan pembelian ulang pada produk Share Tea.

\section{Rumusan Masalah}

Berdasarkan latar belakang yang telah dikemukakan maka yang menjadi rumusan masalah dalam penelitian ini adalah bagaimana pengaruh strategi pemasaran terhadap keputusan pembelian ulang pada produk produk Share Tea di Manado Town Square 3 Kota Manado?

\section{Tujuan Penelitian}

Berdasarkan rumusan masalah, maka tujuan dari penelitian ini yaitu untuk mengetahui pengaruh strategi pemasaran terhadap keputusan pembelian ulang pada produk Share Tea di Manado Town Square 3 Kota Manado.

\section{Manfaat Penelitian}

1. Manfaat bagi peneliti

Memenuhi tugas akhir seminar, menambah pengalaman dan pengetahuan terkait strategi pemasaran suatu perusahaan.

2. Manfaat bagi perusahaan

Menjadi bahan pertimbangan untuk perusahaan agar menerapkan strategi pemasaran yang lebih baik lagi dan mampu melihat peluang-peluang yang ada.

3. Manfaat bagi peneliti selanjutnya

Penelitian ini dapat digunakan sebagai bahan perbandingan atau masukan bagi peneliti dalam melakukan penelitian selanjutnya.

\section{METODOLOGI PENELITIAN}

\section{Waktu dan Tempat Penelitian}

Penelitian ini dilaksanakan selama 3 bulan yaitu dari bulan Januari sampai bulan Maret 2018 dari persiapan sampai penyusunan selesai. Tempat penelitian ini dilaksanakan di Outlet Share Tea Manado Town Square 3.

\section{Metode Pengambilan Sampel}

Dalam penelitian ini digunakan sampel sebesar 60 responden. Penentuan sampel ini dengan menggunakan metode accidental sampling (penentuan sampel berdasarkan kebetulan) yaitu konsumen yang membeli produk Share Tea.

\section{Skala Likert \\ Konsep Pengukuran Variabel}

Jawaban setiap item instrumen yang menggunakan skala likert untuk mengukur Variabel X1, X2, X3 dan X4 sebagai berikut:
Sangat Suka (SS)
Suka (S)
Netral (N)
: Skor 5
: Skor 4
Tidak Suka (TS)
: Skor 3
Sangat Tidak Suka
: Skor 2

Untuk mengukur skor keputusan pembelian ulang (Y) menggunakan skala likert yaitu:

1-6 kali pembelian dalam sebulan: Sangat Jarang $=$ skor 1

7-12 kali pembelian dalam sebulan: Jarang $=$ skor 2

13-18 kali pembelian dalam sebulan: Cukup Sering $=$ skor 3

19-24 kali pembelian dalam sebulan : Sering $=$ skor 4

25-30 kali pembelian dalam sebulan : Sangat Sering $=$ skor 5

\section{Variabel yang Diukur}

1. Product/ Produk (X1)

1) Banyaknya jenis varian produk Share Tea.

2) Kualitas produk Share Tea berkualitas baik.

3) Merek produk Share Tea mudah diingat konsumen.

4) Desain kemasan produk Share Tea menarik.

5) Ukuran produk Share Tea yang disediakan.

6) Tersedianya makanan pendamping.

2. Price/ Harga (X2)

1) Harga produk Share Tea yang ditawarkan terjangkau. 
2) Kesesuaian harga dengan daya beli.

3) Harga yang ditawarkan sesuai dengan kualitas produk.

3. Placel Tempat (X3)

1) Letak tempat yang strategis.

2) Kenyamanan tempat yang di sediakan.

3) Hiasan dalam ruangan yang membuat ruangan menjadi hidup.

4) Kebersihan Tempat.

4. Promotion/ Promosi (X4)

1) Promosi Produk Share Tea yang menarik perhatian konsumen.

2) Adanya potongan harga pada produk Share Tea.

5. Keputusan Pembelian Ulang (Y)

1) Jumlah pembelian ulang oleh konsumen dalam 1 bulan yang membeli produk Share Tea.

\section{Analisis Kuantitatif}

\section{Teknik Analisis Data}

1. Uji Validitas

2. Uji Reliabilitas

3. Uji Asumsi Klasik
a. Uji Normalitas
b. Uji Heterokedastisitas
c. Uji Multikolineritas
d. Uji Autokorelasi

\section{Analisis Regresi Linear Berganda}

Persamaan Regresi dalam penelitian ini adalah untuk mengetahui seberapa besar pengaruh variabel independen atau bebas yaitu Product (X1), Price (X2), Place (X3) dan Promotion (X4), terhadap Keputusan Pembelian (Y).

Model persamaan yang digunakan dalam penelitian ini sebagai berikut:

$$
\mathrm{Y}=\alpha+\beta 1 \mathrm{X} 1+\beta 2 \mathrm{X} 2+\beta 3 \mathrm{X} 3+\beta 4 \mathrm{X} 4+\mathrm{e}
$$

Keterangan:

$\mathrm{Y}=$ Keputusan pembelian ulang

$\alpha=$ Nilai konstan atau tetap, yang merupakan

rata-rata nilai $Y$ pada nilai $\mathrm{X} 1, \mathrm{X} 2, \mathrm{X} 3$ dan

X4 sama dengan nol.

$\beta 1=$ Koefisien regresi dari variabel X1

(Produk/ Product)

$\mathrm{X} 1=$ Produk $($ Product $)$

$\beta 2=$ Koefisien regresi dari variabel X2 (harga/price)

$\mathrm{X} 2=$ Harga $($ price $)$ $\beta 3=$ Koefisien regresi dari variabel X3 (lokasi/place)

$\mathrm{X} 3=$ Promosi (promotion $)$

$\beta 4=$ Koefisian regresi dari variabel $\mathrm{X} 4$ (promosi/ promotion)

$\mathrm{X} 4=$ Lokasi (place)

$\mathrm{e}=$ Standard Error

\section{Pengujian Hipotesis}

1. Uji Statistik F

2. Uji Statistik T

3. Koefisien Determinasi (R2)

\section{HASIL DAN PEMBAHASAN}

\section{Gambaran Umum Daerah Penlitian}

\section{Sejarah Perusahaan}

Share Tea awalnya berdiri di Taiwan Pada tahun 1992. Berawal dari sebuah kepercayaan yang terbina, Share Tea telah berdiri kurang lebih 180 branch yang tersebar diluar Negara Taiwan. Share Tea digagaskan pada bulan Mei 2012 di Jakarta, Indonesia dengan mengambil branch international dari Taiwan sebagai unit bisnis dari KINO GROUP COMPANIES. Bulan September 2012, outlet Share Tea pertama kali dibuka di Plaza Semanggi, Jakarta. Pengembangan Share Tea akan diarahkan kepada "standalone sites" di beberapa kawasan pusat perkantoran dan seterusnya untuk pengembangan di beberapa kota diluar Jakarta. Pengembangan Share Tea dengan sistem waralaba yang telah dipersiapkan akan mempercepat keberadaan Share Tea di area Jakarta dan kota-kota lain di seluruh Indonesia salah satunya di Kota Manado. Share Tea adalah jawaban dari sebuah pertanyaan dikalangan kelas menengah yang mencari sebuah alternatif tempat untuk melepaskan dahaga yang bertaraf internasional, mempunyai kualitas terbaik di seluruh dunia dengan harga terjangkau yang dapat dikunjungi setiap saat.

Share Tea memiliki Visi dan Misi serta Nilai-nilai perusahaan, sebagai berikut:

Visi: Beverages Outlet International yang besar dan tersebar diseluruh Indonesia. 
Misi:

1. Memperkenalkan Minuman Tea dengan kualitas terbaik di dunia.

2. Menyajikan minuman tea dan tapioka pearl dengan kelas international dan menciptakan branch image yang baik di Indonesia.

3. Memberikan pelayanan dengan setulus hati dan higienis.

4. Meningkatkan kesejahteraan seluruh karyawan dan stake holder.

\section{Lokasi Penjualan Share Tea di Kota Manado}

Share Tea sekarang memiliki empat cabang outlet di Kota Manado yang masing-masing bertempat di Manado Town Square 1 lantai 1, IT Center lantai 1, Manado Town Square 3 lantai 3 dan baru dibuka di Transmart Studio Mini lantai 1. Empat cabang outlet Share Tea tersebut memiliki varian produk yang sama. Selain minuman, Share Tea juga menyediakan makanan pendamping seperti kentang goreng, dimsum, dll. Dari keempat cabang outlet Share Tea di Kota Manado, outlet Share Tea Manado Town Square 3 memiliki konsumen dengan jumlah terbanyak dari tiga cabang outlet Share Tea lainnya. Hal tersebut dipengaruhi oleh ramainya pengunjung Mall, serta klasifikasi pengunjungnya yaitu pengunjung kelas menengah keatas.

\section{Varian Produk Share Tea}

Share Tea memiliki beberapa varian produk yang dapat dinikmati di outlet Share Tea sesuai dengan selera masing-masing. Varian-varian produk Share Tea adalah sebagai berikut:
1. Brewed Tea
2. Coffee
3. Fresh Milk
4. Fruit Tea
5. Yakult
6. Frappy
7. Milk Tea
8. Rocksalt \& Cheese
9. Smoothies
10. Snack

Selain minuman dan makanan pendamping, Share Tea juga menyediakan Topping yang dapat dicampur kedalam minuman pilihan sesuai dengan selera konsumen.

Topping yang ada pada produk Share Tea yaitu:
1. Black Pearl
2. Gras Jelly
3. Ice Jelly
4. Rainbow Jelly
5. Coffe Konjac
6. Egg Puding
7. Taro Puding
8. Aloe Vera
9. Read Bean
10. Lychee De Coco

\section{Karakteristik Responden}

Jumlah Responden berdasarkan Jenis Kelamin Tabel 1 Jumlah responden dengan jenis kelamin laki-laki sebanyak 15 orang $(25 \%)$ dan responden dengan jenis kelamin perempuan sebanyak 45 orang (75\%). Maka dapat disimpulkan paling banyak ditemui di outlet Share Tea Manado Town Square 3 yaitu berjenis kelamin perempuan.

\begin{tabular}{lcc}
\multicolumn{2}{c}{ Tabel 1. Jumlah Responden berdasarkan Jenis Kelamin } \\
\hline Jenis Kelamin & Jumlah Responden & Persentase $(\%)$ \\
\hline Laki-laki & 15 & 25 \\
Perempuan & 45 & 75 \\
\hline \multicolumn{1}{c}{ Total } & 60 & 100 \\
\hline
\end{tabular}

\section{Jumlah Responden berdasarkan kelompok Usia}

Tabel 2 menunjukkan bahwa jumlah responden dengan usia antara 16-24 tahun mendominasi konsumen yang berada di Share $T e a$, yaitu sebanyak 45 orang dari 60 konsumen yang diwawancarai.

Tabel 2. Jumlah Responden berdasarkan Kelompok Usia

\begin{tabular}{lcr}
\hline Usia & Jumlah Responden & Persentase (\%) \\
\hline $16-24$ & 45 & 75 \\
$25-33$ & 9 & 15 \\
$34-42$ & 6 & 10 \\
\hline Total & 60 & 100 \\
\hline
\end{tabular}

\section{Jumlah Responden berdasarkan Jenis Pekerjaan}

Tabel 3 menunjukkan bahwa, Faktor utama yang menjadikan pelajar/mahasiswa sebagai konsumen terbanyak dikarenakan produk dan varian rasa yang ditawarkan oleh Share Tea sangat sesuai dengan selera remaja saat ini.

Tabel 3. Jumlah Responden berdasarkan Jenis Pekerjaan

\begin{tabular}{lcr}
\hline Jenis Pekerjaan & Jumlah Responden & Persentase (\%) \\
\hline Pelajar/Mahasiswa & 45 & 75 \\
PNS & 7 & 11,7 \\
Wiraswasta & 2 & 3,3 \\
Pegawai Swasta & 6 & 10 \\
\hline \multicolumn{1}{c}{ Total } & 60 & 100 \\
\hline
\end{tabular}


Jumlah Responden Berdasarkan Pendapatan

Tabel 4 menunjukkan bahwa, jumlah responden terbanyak berdasarkan pendapatan yaitu yang belum berpenghasilan sebanyak 40 orang. Esponden ini terdiri dari siswa dan mahasiswa yang menjadi konsumen produk Share Tea.

Tabel 4. Jumlah Responden berdasarkan Pendapatan

\begin{tabular}{lcr}
\hline \multicolumn{1}{c}{ Pendapatan/bulan } & $\begin{array}{c}\text { Jumlah } \\
\text { Responden }\end{array}$ & Persentase (\%) \\
\hline Belum Ada Penghasilan & 40 & 66,7 \\
$<500.000$ & 2 & 3,3 \\
$500.000-1.000 .000$ & 6 & 10 \\
$1.000 .000-2.500 .000$ & 3 & 5 \\
$2.500 .000-5.000 .000$ & 7 & 11,7 \\
$>5.000 .000$ & 2 & 3,3 \\
\hline Total & 60 & 100 \\
\hline
\end{tabular}

\section{Jumlah Responden berdasarkan Pendidikan Terakhir}

Tabel 5 menunjukkan bahwa, konsumen Share Tea dengan jenjang pendidikan terakhir SMA dengan persentase $65 \%$ merupakan konsumen paling banyak ditemui di outlet Share $T e a$, diikuti konsumen dengan jenjang pendidikan terakhir S1 dengan persentase 28,3\%, kemudian konsumen dengan jenjang pendidikan terakhir SMP dengan persentase 5\%, selanjutnya konsumen dengan jenjang pendidikan terakhir Diploma dengan persentase $1,7 \%$, dan kosnumen yang tidak ditemui di outlet adalah konsumen dengan jenjang pendidikan S2-S3 dengan persentase $0 \%$.

Tabel 5. Jumlah Responden berdasarkan Pendidikan Terakhir

\begin{tabular}{ccr}
\hline $\begin{array}{c}\text { Pendidikan } \\
\text { Terakhir }\end{array}$ & Jumlah Responden & Frekuensi (\%) \\
\hline SMP & 3 & 5 \\
SMA & 39 & 65 \\
Diploma & 1 & 1,7 \\
S1 & 17 & 28,3 \\
S2-S3 & 0 & 0 \\
\hline Total & 60 & 100 \\
\hline
\end{tabular}

\section{Jumlah Responden berdasarkan Keputusan Pembelian Ulang}

Tabel 6 menunjukkan bahwa frekuensi pembelian Produk Share Tea yang dilakukan konsumen 7-12 kali dalam sebulan yakni sebanyak 22 orang (36,7\%), kemudian frekuensi pembelian produk Share Tea yang dilakukan konsumen 13 - 18 kali dalam sebulan yakni sebanyak 18 orang (30\%), selanjutnya frekuensi pembelian Produk Share Tea yang dilakukan konsumen 1-6 kali dalam sebulan yakni sebanyak 12 orang (20\%), diikuti frekuensi pembelian Produk Share Tea yang dilakukan konsumen 1924 kali dalam sebulan yakni sebanyak 6 orang (10\%), dan frekuensi pembelian Produk Share Tea yang dilakukan konsumen 25-30 kali dalam sebulan yakni sebanyak 2 orang $(3,3 \%)$.

Tabel 6. Jumlah Responden berdasarkan Keputusan Pembelian Ulang

\begin{tabular}{ccr}
\hline $\begin{array}{c}\text { Keputusan } \\
\text { Pembelian Ulang }\end{array}$ & $\begin{array}{c}\text { Jumlah } \\
\text { Responden }\end{array}$ & Frekuensi (\%) \\
\hline $1-6$ kali & 12 & 20 \\
$7-12$ kali & 22 & 36,7 \\
$13-18$ kali & 18 & 30 \\
$19-24$ kali & 6 & 10 \\
$25-30$ kali & 2 & 3,3 \\
\hline Total & 60 & 100 \\
\hline
\end{tabular}

\section{Uji Validitas}

\section{Uji Instrumen}

Hipotesis:

$\mathrm{H} 0=$ Butir pertanyaan tidak valid

$\mathrm{H} 1$ = Butir pertanyaan valid

Taraf signifikasi:

$$
\alpha=5 \%
$$

Kriteria Uji:

Tolak H0 jika $r$ hitung $>0,3$ atau nilai $p<0,000$.

Menurut Azwar (1999), semua item yang mencapai koefisien korelasi minimal 0,30 daya pembedanya dianggap memuaskan. Berdasarkan hasil uji validitas variabel produk (X1), maka diketahui bahwa soal nomor 1, 2, 3, 4, 5 dan 6 memiliki nilai $r \geq 0,3$ atau nilai $p<0,000$, yaitu pernyataan nomor 1 memiliki $\mathrm{r}$ sebesar 0,645 , pernyataan nomor 2 memiliki r 0,745 , pernyataan nomor 3 memiliki $\mathrm{r}$ sebesar 0,654 , pernyataan nomor 4 memiliki $\mathrm{r}$ sebesar 0,660 , pernyataan nomor 5 memiliki $r$ sebesar 0,487 , dan pernyataan nomor 6 memiliki $r$ sebesar 0,641 maka keenam soal tersebut dinyatakan valid. Data hasil validitas variabel produk tersebut untuk lebih jelasnya dapat dilihat pada Tabel 7.

\begin{tabular}{cccc}
\multicolumn{4}{c}{ Tabel 7. Hasil Uji Validitas Product $(\mathbf{X 1})$} \\
\hline $\begin{array}{c}\text { Butir } \\
\text { Pertanyaan }\end{array}$ & Nilai r & $\mathbf{P}$ & Keterangan \\
\hline X1_1 & 0,645 & 0,000 & Valid \\
X1_2 & 0,745 & 0,000 & Valid \\
X1_3 & 0,654 & 0,000 & Valid \\
X1_4 & 0,660 & 0,000 & Valid \\
X1_5 & 0,487 & 0,000 & Valid \\
X1_6 & 0,641 & 0,000 & Valid \\
\hline
\end{tabular}


Berdasarkan hasil uji validitas variabel price (X2), maka diketahui bahwa soal nomor 1, 2, dan 3 memiliki nilai $\mathrm{r} \geq 0,3$ atau nilai $\mathrm{p}<$ 0,000 , yaitu pernyataan nomor 1 memiliki $r$ sebesar 0,904 , pernyataan nomor 2 memiliki $\mathrm{r}$ 0,926, dan pernyataan nomor 3 memiliki $r$ sebesar 0,844, maka ketiga soal tersebut dinyatakan valid. Data hasil validitas variabel price tersebut untuk lebih jelasnya dapat dilihat pada Tabel 8.

Tabel 8. Hasil Uji Validitas Price (X2)

\begin{tabular}{cccc}
\hline $\begin{array}{c}\text { Butir } \\
\text { Pertanyaan }\end{array}$ & Nilai r & P & Keterangan \\
\hline X2_1 & 0,904 & 0,000 & Valid \\
X2_2 & 0,926 & 0,000 & Valid \\
X2_3 & 0,844 & 0,000 & Valid \\
\hline
\end{tabular}

Berdasarkan hasil uji validitas variabel place (X3), maka diketahui bahwa soal nomor $1,2,3$ dan 4 memiliki nilai $r \geq 0,3$ atau nilai $p<$ 0,000 , yaitu pernyataan nomor 1 memiliki $r$ sebesar 0,763 , pernyataan nomor 2 memiliki $r$ 0,812 , pernyataan nomor 3 memiliki $r$ sebesar 0,795 , dan pernyataan nomor 4 memiliki $r$ sebesar 0,449 maka keempat soal tersebut dinyatakan valid. Data hasil validitas variabel place tersebut untuk lebih jelasnya dapat dilihat pada Tabel 9.

Tabel 9. Hasil Uji Validitas Place (X3)

\begin{tabular}{cccc}
\hline $\begin{array}{c}\text { Butir } \\
\text { Pernyataan }\end{array}$ & Nilai r & p & Keterangan \\
\hline X3_1 & 0,763 & 0,000 & Valid \\
X3_2 & 0,812 & 0,000 & Valid \\
X3_3 & 0,795 & 0,000 & Valid \\
X3_4 & 0,449 & 0,000 & Valid \\
\hline
\end{tabular}

Berdasarkan hasil uji validitas variabel promotion (X4), maka diketahui bahwa soal nomor 1 , dan 2 memiliki nilai $r \geq 0,3$ atau nilai $\mathrm{p}<0,000$, yaitu pernyataan nomor 1 memiliki $r$ sebesar 0,936, dan pernyataan nomor 2 memiliki $r$ 0,945, maka keempat soal tersebut dinyatakan valid. Data hasil validitas variabel promotion tersebut untuk lebih jelasnya dapat dilihat pada Tabel 10.

Tabel 10. Hasil Uji Validitas Promotion (X4)

\begin{tabular}{cccc}
\hline $\begin{array}{c}\text { Butir } \\
\text { Pertanyaan }\end{array}$ & Nilai $\mathbf{r}$ & $\mathbf{P}$ & Keterangan \\
\hline X4_1 & 0,936 & 0,000 & Valid \\
X4_2 & 0,945 & 0,000 & Valid \\
\hline
\end{tabular}

\section{Uji Reliabilitas}

a. X1 (Produk)

Cronbach's Alpha = 0,6899

Interprestasi:

Berdasarkan hasil output diatas, dapat dilihat nilai pada kolom Cronbach's Alpha adalah 0,6899. Karena nilai tersebut lebih besar jika dibandingkan dengan nilai minimal Cronbach's Alpha yaitu 0,60, maka dapat disimpulkan bahwa instrumen penelitian yang digunakan untuk mengukur variabel produk dapat dikatakan reliabilitasnya tinggi.

b. X2 (Price)

Cronbach's Alpha $=0,8683$

Interprestasi:

Berdasarkan hasil output diatas, dapat dilihat nilai pada kolom Cronbach's Alpha adalah 0,8683 . Karena nilai tersebut lebih besar jika dibandingkan dengan nilai minimal Cronbach's Alpha yaitu 0,60, maka dapat disimpulkan bahwa instrumen penelitian yang digunakan untuk mengukur variabel price dapat dikatakan reliabilitasnya tinggi.

c. X3 (Place)

Cronbach's Alpha = 0,6494

Interprestasi:

Berdasarkan hasil output diatas, dapat dilihat nilai pada kolom Cronbach's Alpha adalah 0,6494. Karena nilai tersebut lebih besar jika dibandingkan dengan nilai minimal Cronbach's Alpha yaitu 0,60, maka dapat disimpulkan bahwa instrumen penelitian yang digunakan untuk mengukur variabel place dapat dikatakan reliabilitasnya tinggi.

d. X4 (Promotion)

Cronbach's Alpha $=0,8686$

Interprestasi:

Berdasarkan hasil output diatas, dapat dilihat nilai pada kolom Cronbach's Alpha adalah 0,8686 . Karena nilai tersebut lebih besar jika dibandingkan dengan nilai minimal Cronbach's Alpha yaitu 0,60, maka dapat disimpulkan bahwa instrumen penelitian yang digunakan untuk mengukur variabel promotion dapat dikatakan reliabilitasnya tinggi.

\section{Asumsi Klasik \\ Asumsi Multikolinieritas \\ Tabel 11 menunjukkan bahwa diperoleh nilai VIF yaitu masing-masing variabel kurang dari 10. Sehingga dapat disimpulkan bahwa tidak terjadi pelanggaran asumsi multikolinieritas antar variabel bebas dalam model regresi tersebut.}


Tabel 11. Hasil Uji Asumsi Multikolinieritas

\begin{tabular}{lccc} 
Predictor & Coef & P & VIF \\
\hline Constant & $-3,9726$ & 0,000 & \\
X1 & 0,11478 & 0,002 & 1,526 \\
X2 & 0,05760 & 0,228 & 1,131 \\
X3 & 0,09777 & 0,018 & 1,420 \\
X4 & 0,18810 & 0,000 & 1,188 \\
\hline
\end{tabular}

\section{Asumsi Heteroskedasitas}

Gambar 1 menunjukkan bahwa tidak ada pola yang jelas serta titik menyebar diatas dan dibawah angka 0 pada sumbu Y, maka tidak terjadi heterokedastisitas pada model regresi.

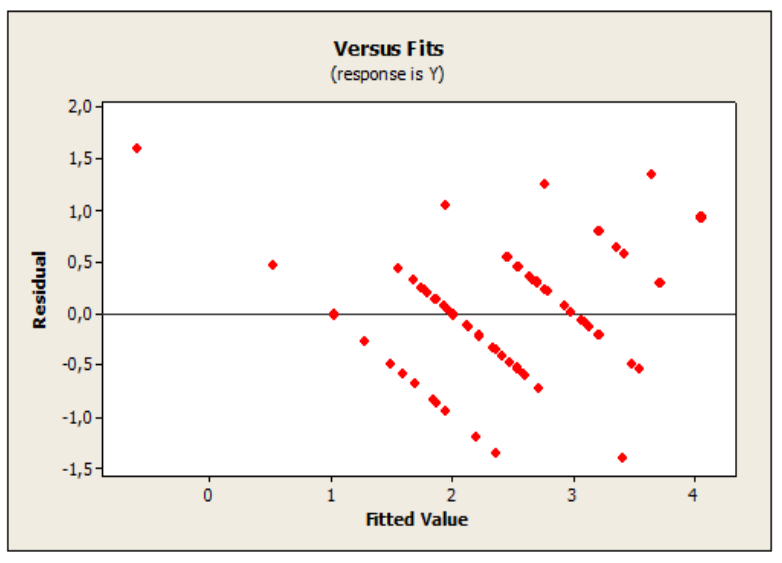

Gambar 1. Versus Fits

\section{Asumsi Normalitas}

Gambar 2 menunjukkan bahwa hasil output diperoleh nilai signifikansi sebesar $>0,150$. Karena nilai signifikansi lebih dari 5\%, Hal ini terlihat dari titik yang menyebar di sekitar grafik normal dan dari titik-titik yang menyebar disekitar garis diagonal dan penyebarannya mengikuti garis diagonal. maka dapat disimpulkan bahwa residual berdistribusi normal.

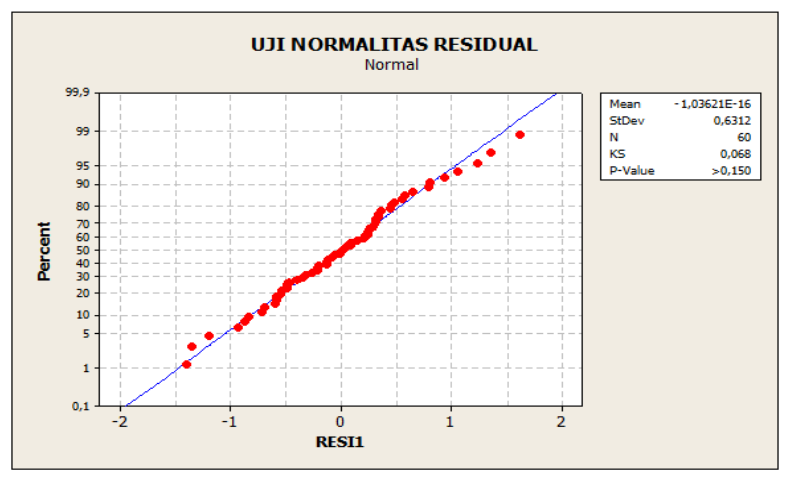

Gambar 2. Uji Normalitas Residual

\section{Asumsi Autokorelasi}

Hasil perhitungan menjelaskan bahwa nilai Durbin-Watson yang ditemukan adalah sebesar 1,76564. Oleh karena nilai terletak antara dU (1,727) dan 4-dU (2,273), maka dapat disimpulkan bahwa tidak terjadi autokorelasi untuk persamaan regresi variabel produk, harga, promosi, dan lokasi terhadap keputusan pembelian ulang pada produk Share Tea di Manado Town Square 3.

\section{Koefisien Determinasi}

Nilai yang dipakai dalam penelitian ini adalah nilai Adjusted R2 karena nilai ini dapat naik atau turun apabila satu variabel bebas ditambahkan ke dalam model yang diuji. Nilai Adjusted R2 dapat dilihat berikut ini:

$\mathrm{S}=0,653758 \mathrm{R}-\mathrm{Sq}=62,3 \% \quad \mathrm{R}-\mathrm{Sq}(\mathrm{adj})=59,6 \%$

Berdasarkan hasil diatas dapat dilihat bahwa nilai adjusted $\mathrm{R}$ square adalah $59.6 \%$. Hal ini berarti bahwa keputusan pembelian ulang dipengaruhi oleh produk, price, place, dan promotion sebesar $59,6 \%$, sedangkan $40,4 \%$ sisanya dipengaruhi faktor lain yang tidak diteliti.

\section{Model}

\section{Analisis Regresi Berganda} adalah:

Hasil persamaan regresi linear berganda $\mathrm{Y}=-3,97+0,115 \mathrm{X} 1+0,0576 \mathrm{X} 2+0,0978 \mathrm{X} 3$ $+0,188 \mathrm{X} 4$

Interprestasi:

Nilai konstanta adalah $-3,97$ artinya apabila variabel produk (X1), price (X2), place (X3), dan promotion (X4) bernilai nol, maka nilai keputusan pembelian ulang (Y) adalah -3,97.

Koefisien regresi variabel produk (X1) adalah 0,115 . Artinya apabila variabel produk meningkat 1 poin maka akan meningkatkan nilai keputusan pembelian ulang $(\mathrm{Y})$ sebesar 0,115 poin.

Koefisien regresi variabel price (X2) adalah 0,0576 . Artinya apabila variabel price meningkat 1 poin maka akan meningkatkan nilai keputusan pembelian ulang (Y) sebesar 0,0576 poin.

Koefisien regresi variabel place (X3) adalah 0,0978 . Artinya apabila variabel place meningkat 1 poin maka akan meningkatkan nilai keputusan pembelian ulang $(\mathrm{Y})$ sebesar 0,115 poin.

Koefisien regresi variabel promotion (X4) adalah 0,188. Artinya apabila variabel promotion meningkat 1 poin maka akan meningkatkan nilai keputusan pembelian ulang $(\mathrm{Y})$ sebesar 0,188 poin. 


\section{Uji Parsial (t Test)}

Hipotesis:

H0 : Variabel independen tidak berpengaruh terhadap variabel keputusan pembelian ulang

H1 : Variabel independen berpengaruh terhadap variabel keputusan pembelian ulang

Kriteria Uji:

Tolak H0 jika nilai signifikansi $<5 \%$. Hasil uji Parsial berdasarkan Tabel 12 menunjukkan bahwa:

\begin{tabular}{cccc}
\multicolumn{4}{l}{ Tabel 12. Hasil uji Parsial (T) } \\
\hline Predictor & Coef & T & P \\
\hline Constant & $-3,9726$ & $-5,07$ & 0,000 \\
X1 & 0,11478 & 3,31 & 0,002 \\
X2 & 0,05760 & 1,22 & 0,228 \\
X3 & 0,09777 & 2,43 & 0,018 \\
X4 & 0,18810 & 4,45 & 0,000 \\
\hline
\end{tabular}

Interprestasi:

Nilai thitung variabel produk (X1) adalah sebesar 3,31 dengan nilai signifikansi sebesar 0,002. Karena nilai signifikansi lebih kecil dibandingkan 5\%, maka dapat disimpulkan bahwa variabel produk (X1) berpengaruh terhadap variabel keputusan pembelian ulang (Y).

Berdasarkan hasil penelitan, konsumen Share Tea di Manado Town Square 3 tidak hanya memandang harga, tetapi juga melihat kualitas produk dan penampilan produk Share Tea itu sendiri. Penampilan produk Share Tea yang menarik dan memiliki banyak varian akan menarik minat pembelian konsumen untuk membeli produk Share Tea. Selain itu, produk tidak hanya meliputi atribut fisik saja, tetapi juga mencakup sifat-sifat nonfisik, misalnya harga, merek, semua unsur tersebut dipandang sebagai alat pemuas kebutuhan.

Nilai t hitung variabel price (X2) adalah sebesar 1,22 dengan nilai signifikansi sebesar 0,228 . Karena nilai signifikansi lebih besar dibandingkan 5\%, maka dapat disimpulkan bahwa variabel price (X2) tidak berpengaruh terhadap variabel keputusan pembelian ulang (Y).

Berdasarkan hasil penelitian, perusahaan Share Tea selalu berusaha memberikan produk dengan kualitas baik. Hal ini ditunjukkan dari tersedianya produk-produk yang berkualitas sesuai dengan standart kualitas yang diinginkan oleh konsumen, dan harga produk yang ditawarkan sesuai dengan manfaat yang diperoleh konsumen, sehingga konsumen dapat merasa senang jika membeli produk Share Tea di Manado Town Square 3. Selain itu, konsumen telah mengetahui harga produk Share Tea sebelumnya. Sehingga, konsumen menyatakan bahwa harga produk Share Tea yang ditawarkan terjangkau, kesesuaian harga sesuai dengan daya beli konsumen dan harga yang ditawarkan sesuai dengan kualitas produk Share Tea itu sendiri.

Nilai t hitung variabel place (X3) adalah sebesar 2,43 dengan nilai signifikansi sebesar 0,018. Karena nilai signifikansi lebih kecil dibandingkan 5\%, maka dapat disimpulkan bahwa variabel place (X3) berpengaruh terhadap variabel keputusan pembelian ulang (Y).

Berdasarkan hasil penelitian, lokasi outlet Share Tea yang berada di Manado Town Square 3 memiliki letak yang strategis. Hal ini, karena dari keempat cabang outlet Share Tea di Kota Manado, outlet Share Tea Manado Town Square 3 memiliki konsumen dengan jumlah terbanyak dari tiga cabang outlet Share Tea lainnya. Selain itu, konsumen menyatakan outlet Share Tea memiliki Penataan dekorasi interior yang menarik dan kebersihan yang selalu diperhatikan sehingga membuat konsumen merasa nyaman berada di outlet Share Tea Manado Town Square 3.

Nilai $\mathrm{t}$ hitung variabel promotion (X4) adalah sebesar 4,45 dengan nilai signifikansi sebesar 0,000. Karena nilai signifikansi lebih kecil dibandingkan $5 \%$, maka dapat disimpulkan bahwa variabel promotion (X4) berpengaruh terhadap variabel keputusan pembelian ulang $(\mathrm{Y})$.

Berdasarkan hasil penelitian, Strategi promosi dapat menarik minat konsumen untuk melakukan pembelian ulang pada produk Share Tea. Salah satu promosi yang dilakukan oleh Share Tea yaitu adanya potongan harga yang di berikan ke konsumen, potongan harga ini diberikan apabila konsumen melakukan pembelian 2 produk Share Tea dan promosi dalam bentuk kartu yang di cap. Apabila kartu tersebut mencapai 10 cap maka konsumen mendapat 1 produk Share Tea secara gratis. Selain itu, promosi uang dilakukan oleh Share Tea yaitu berupa X-Banner yang terletak di depan outlet Share Tea Manado Town Square 3 menarik minat konsumen untuk membeli produk Share Tea karena setiap bulan Share Tea selalu mengeluarkan 1 varian rasa pada daftar menu varian produk Share Tea. 


\section{Uji F (Uji simultan)}

HO : variabel independen secara bersamasama (simultan) tidak mempengaruhi variabel keputusan pembelian ulang

H1 : variabel independen secara bersamasama (simultan) mempengaruhi variabel keputusan pembelian ulang.

Kriteria uji

Tolak H0 jika nilai signifikansi $<5 \%$

\section{Analysis of Variance}

Tabel 13 menunjukkan bahwa diperoleh nilai $F$ sebesar 22,75 dengan nilai signifikansi 0,000 . Karena nilai signifikansi kurang dari 5\% maka H0 ditolak, sehingga dapat disimpulkan bahwa variabel secara bersamasama (simultan) mempengaruhi variabel keputusan pembelian ulang.

Tabel 13. Hasil uji Simultan (F)

\begin{tabular}{lccccc}
\hline \multicolumn{1}{c}{ Source } & DF & SS & MS & F & P \\
\hline Regression & 4 & 38,8930 & 9,7233 & 22,75 & 0,000 \\
$\begin{array}{l}\text { Residual } \\
\text { Error }\end{array}$ & 55 & 23,5070 & 0,4274 & & \\
\hline Total & 59 & 62,4000 & & & \\
\hline
\end{tabular}

\section{KESIMPULAN DAN SARAN}

\section{Kesimpulan}

Berdasarkan hasil analisis data dan pembahasan dapat ditarik kesimpulan sebagai berikut:

a. Product berpengaruh terhadap keputusan pembelian ulang pada produk Share Tea. Berdasarkan hasil penelitian, konsumen menilai bahwa kualitas produk Share Tea yang diberikan berkualitas baik dan tersedia banyaknya jenis varian. Oleh karena itu, produk Share Tea dapat memenuhi keinginan konsumen sehingga mempengaruhi untuk melakukan pembelian ulang di outlet Share Tea Manado Town Square 3.

b. Price tidak berpengaruh terhadap keputusan pembelian ulang pada produk Share Tea. Berdasarkan hasil penelitian, konsumen menilai harga produk Share Tea sesuai dengan daya beli konsumen serta kualitas yang diterima oleh konsumen. Selain itu, konsumen telah mengetahui harga produk Share Tea itu sendiri, sehingga tidak mempengaruhi keputusan pembelian ulang konsumen terhadap produk Share Tea.

c. Place berpengaruh terhadap keputusan pembelian ulang pada produk Share Tea. Berdasarkan hasil penelitian, konsumen menilai bahwa outlet Share Tea memiliki letak tempat yang strategis serta desain outlet yang menarik, sehingga konsumen merasa nyaman berada di dalam outlet Share Tea Manado Town Square 3.

d. Promotion berpengaruh terhadap keputusan pembelian ulang pada produk Share Tea. Berdasarkan hasil penelitian, Strategi promosi dapat menarik minat konsumen untuk melakukan pembelian ulang pada produk Share Tea. Salah satu promosi yang dilakukan oleh Share Tea yaitu adanya potongan harga yang di berikan ke konsumen berupa potongan harga.

\section{Saran}

Setelah penulis melakukan penelitian dan pengamatan mengenai Pengaruh Strategi Pemasaran Terhadap Keputusan Pembelian Ulang Pada Produk Share Tea di Manado Town Square 3, maka dikemukakan saran sebagai berikut:

1. Bagi perusahaan Share Tea diharapkan tetap dapat meningkatkan inovasi dan mempertahankan kualitas produk Share Tea, sehingga konsumen semakin loyal untuk melakukan pembelian ulang terhadap produk Share Tea.

2. Bagi karyawan hendaknya selalu tanggap dengan segala kebutuhan pengunjung secara lebih cepat dan tepat, baik dalam memberikan bantuan yang dibutuhkan, agar konsumen mendapatkan kepuasan atas jasa yang diberikan dan akan tetap melakukan pembelian ulang. 
DAFTAR PUSTAKA

Azwar, Saifuddin. 1999. Reliabilitas Dan Validitas. Sigma Alpha. Yogyakarta.
Manasaputri Sri Autami, N. L. M., \& Suasana, I. 2015. Pengaruh Retail Mix Terhadap Keputusan Pembelian Konsumen Pada Gerai C'hatime. E-Jurnal Manajemen Universitas Udayana. Bandung. 